\title{
Socio-Economic Aspects of Digitalizing the Diagnostic Process in Urology
}

\author{
Zinchenko I.V.* \\ Rossosh Interdistrict Urological Center \\ Rossosh, Russia \\ e-mail: iv_zinchenko84@mail.ru
}

Popov S.V.

Voronezh State Medical University named after N.N. Burdenko

Voronezh, Russia

e-mail: sergeyvpopov@rambler.ru

\author{
Titova L.A. \\ Voronezh State Medical University named after \\ N.N. Burdenko \\ Voronezh, Russia \\ e-mail: liliant@mail.ru
}

\section{Popov I. V.}

Voronezh State Agrarian University named after Emperor Peter the Great

Voronezh, Russia

e-mail: iblackmore@rambler.ru

\begin{abstract}
This article highlights socially significant issues of organization and digitalization of the regional system of medical urological care in Russia, which determine its diagnostic and economic efficiency. The questions of the organization of the regional system of medical urological care in Russia are highlighted. It is based on the principles of prevention and active early detection of diseases. Of particular importance for ensuring the correct and efficient organization of this system of medical care is the inter-district urological centers. They focus on qualified specialists who have sufficient instrumental base for carrying out the necessary diagnostic measures. The data summarizing the results of diagnostic work on the basis of the Rossosh inter-district urological center during 2018 is presented. The contingent of the examined is characterized taking into account their age and place of residence. The most important place in the algorithm for examining patients with a urological profile is given to ultrasound, which allows correct assessment of the zonal architectonics of the prostate gland. The experience of using ultrasound for the detection of prostate diseases in men of various age groups is presented. The summary values of the identified ultrasound changes associated with various nosolic forms are given. The methodological difficulties of ultrasound detection of prostate cancer are highlighted. An analysis of the significance of the transrectal ultrasound method of research was carried out, which allowed determining ways to increase its information content to ensure effective ultrasound diagnosis of prostate cancer.
\end{abstract}

Keywords - socially significant issues, economic efficiency, medical care, interdistrict urological center, diagnostic measures, ultrasound.

\section{INTRODUCTION}

One of the main components of the National Healthcare Project is to increase the diagnostic and economic efficiency of the fight against cancer using digital technologies for standardized processing of survey data, analysis of the data obtained and forecasting the needs of the population in specialized medical care. The increase in cancer incidence and high mortality from malignant lesions of various organs and systems of the body are an urgent medical and social problem.
In 2018, 624709 new cases of cancer were registered in Russia (285 949 for males and 338760 for females). The growth amounted to $1.2 \%$ compared to 2017 and $23.1 \%$ to the level of 2008. The incidence of malignant neoplasms was 425.4 people per 100 thousand of the population. As of 2018, in Russia there are more than 3.76 million people with cancer, or $2.6 \%$ of the country's population (in 2017, slightly more than 3.63 million people, $2016-3.51$ million). Of these, $0.7 \%$ are patients under 18 years of age; patients of working age (from 18 years old) and retirement age (women from 55 years old and men from 60 years old) $-35.9 \%$ and $62.5 \%$, respectively. 2.05 million patients or $54.4 \% \quad(53.9 \%$ in 2017) of all patients with malignant neoplasms were monitored in specialized oncological medical institutions for 5 years or more. Among all cancer patients, $18.4 \%$ have malignant neoplasms of the mammary gland, $7 \%$ have uterine bodies, $6.3 \%$ have the prostate, $5.8 \%$ have the colon, $5.7 \%$ have lymphatic and hematopoietic tissue. As follows from the above data, prostate cancer $(\mathrm{PCa})$ is one of the most important problems of modern oncourology. The task of effectively combating this disease is relevant for specialized specialists all over the world. Thus, to date, prostate cancer occupies the 2nd place in the world among all male malignancies and the 6th place among causes of cancer death [1].

A significant drawback of the organization of medical care for prostate cancer in the Russian Federation (RF) is its later detection, which leads to a high proportion of advanced cases of the disease. If in the USA the number of patients with stage III and IV prostate cancer is $19 \%$ of the total number of cancer patients who have this disease for the first time, then in the Russian Federation it is much more $-52 \%$. The need for a thorough epidemiological analysis of the disease and rational monitoring of the development of precancerous processes, when there is a cellular transformation to the state of early stromal invasion and the formation of a mature invasive tumor, is obvious. The need for early detection of PCa dictates the feasibility of optimal structuring of diagnostic and therapeutic measures for the most efficient use of human 
resources and the capabilities of medical institutions. In this regard, the problem of organizing a multi-level system of providing medical care to the population, which involves a significant improvement in the detection of prostate cancer in the early stages of its development and provides an effective algorithmization of therapeutic measures, has become particularly urgent. The main areas of such work are seen:

- medical sorting and determination of individual patient routes at all stages of the necessary medical, wellness, rehabilitation and preventive care;

- regulation of goals, objectives, volumes and technical level of medical care at each successive stage of treatment in accordance with state medical, technological and economic standards;

- integration of individual elements of primary, prehospital, inpatient, post-hospital and other types of medical and health-care services into a single medical and technological complex, which in the most rational form ensures the continuity, continuity, adequacy and timeliness of all necessary procedures and procedures;

- uniform approaches to the methodology and technology of the treatment process, the conditions of patient care, the financing system, quality control, etc. at all levels and stages of care [2].

It should be noted that the incidence of prostate cancer in the Voronezh region in recent years exceeds this indicator for the Russian Federation as a whole, which indicates a tense onco-epidemiological situation in the region that requires effective measures. Research Institute of Urology and Interventional Radiology, together with the government and medical institutions of the Voronezh region, has developed and since 2011 implemented a multi-level system of medical care in urology, based on the principles of prevention and active early detection of diseases. Medical care for prostate cancer in the Voronezh region was divided into 4 levels (stages). The first level is the primary medical link - district doctors, general practitioners, family doctors, paramedics, etc. The task of the first stage was to form a risk group for prostate cancer. To implement this task, the following activities were carried out:

- training of primary care physicians in terms of cancer alertness regarding prostate cancer;

- compiling a list of men over 45 attached to each medical site;

- creating a network survey schedule for men over 45;

- formation of a risk group for prostate cancer.

\section{MATERIALS AND METHODS}

The surveys were conducted using the International Prostate Symptom Score (IPSS) and questions from the individual prostate cancer risk profile compiled by the Prostate Cancer Research Foundation (SWOP). Risk of prostate cancer was assessed using a Risk Counter 1 of the SWOP nomogram based on three characteristics: age, heredity in prostate cancer, and urination disorders. Men with an average and increased risk of prostate cancer were sent to the next level.

At the second level, medical care is provided in interdistrict urological centers (IUC), which were created at the rate of 1 IUC per 300,000 populations. The objective of this stage was to stratify risk groups based on the results of a special study. For this, the urologist evaluated all the results obtained in the first stage, and determined the indications for performing a blood test for prostate specific antigen (PSA). According to the results of a blood test for PSA and the rest of the special examination (data of a digital rectal examination, the volume of the prostate gland and the presence of hypoechoic lesions during ultrasound), indications for biopsy of the prostate gland were determined using Counter 3 of the SWOP nomogram. It should be noted that the prerequisites for the implementation of the task of the second stage were the standardization of training of medical specialists (urologists), material and technical equipment of the workplace and diagnostic methods (PSA, prostate biopsy, ultrasound, etc.) under the guidance of specialists from the Research Institute of Urology and Interventional radiology. When creating standards, they were guided by international and domestic recommendations based on the principles of evidence-based medicine. After morphological verification of prostate cancer, patients were referred to the third level.

The third stage of assistance was carried out on the basis of a regional (regional) urological center. The purpose of this step of the examination was to establish the stage of the disease by conducting an additional examination (computed or magnetic resonance imaging of the pelvic organs, osteoscintigraphy, repeated biopsy of the prostate gland according to indications, etc.) as well as the choice of the final tactics of patient management, including radical surgical treatment. A prerequisite for full-fledged work at this stage, as at the previous one, was the standardization of training of medical specialists, equipment of a medical institution, diagnostic and treatment methods (indications, contraindications, performance technique) under the guidance of the Research Institute of Urology and Interventional Radiology. In complex clinical cases, including complications of the previous treatment, patients were referred to the fourth level.

The fourth level is the center of high-tech medical care, which was the Institute of Urology and Interventional Radiology. The objectives of this stage were:

- treatment of complex cases of the disease and correction of complications after previous treatment;

- quality control of all types of previous medical care according to indicators introduced for each level;

- methodological assistance to the previous stages.

To implement these tasks, employees of the Research Institute of Urology and Interventional Radiology created advisory and educational portals, organized regular visiting cycles and meetings on training, training of regional specialists, as well as monitoring their activities in the framework of this program $[3,4]$. 
It is important to ensure the correct and effective organization of this system of medical care is the IUC. Qualified specialists are concentrated in them, they have sufficient instrumental base for carrying out the necessary diagnostic measures. The most important place in the algorithm for examining patients with a urological profile is given to ultrasound, which allows correct assessment of the zonal architectonics of the prostate gland. PCa develops with different frequencies in each zone, and this frequency is not proportional to the mass of glandular tissue in it. The central and peripheral zones - the largest areas of the prostate together make up about $95 \%$ of the volume of prostate tissue. The central zone surrounds the vas deferens on their way from the base of the prostate to the seminal tubercle. The central zone occupies 15-20\% of the volume of the gland, however, only $5-10 \%$ of all prostate cancer occurs in it. Peripheral zone is a part of the gland palpable through the rectum through the rectum. It surrounds the central zone, includes $70 \%$ of glandular tissue, and about $70 \%$ of prostate adenocarcinomas originate in it. Transitional zone - paired sections of the prostate located bilaterally with respect to the prostatic urethra at the level of the seminal tubercle, occupy the remaining $5 \%$ of the volume of the gland. The most common pathology of this zone is benign prostatic hyperplasia (BPH), which can lead to a significant increase in these zones, sometimes exceeding the rest of the prostate in volume. In this zone, cancer develops less frequently than BPH; its frequency is about $20 \%$. Periurethral glands are located between the prostatic urethra and the proximal smooth muscle sphincter of the bladder. The fibromuscular stroma occupies the anterior surface of the prostate and consists mainly of muscle tissue. Adenocarcinomas in the last two zones do not develop. A typical echographic manifestation of prostate cancer is hypoechoic formation in the peripheral area of the prostate gland [5-10].

It should be noted that transrectal ultrasound examination (TRUS) should be used for effective ultrasound detection of prostate cancer. In contrast to transabdominal ultrasound scanning of the prostate gland, the use of high-frequency transrectal ultrasound sensors makes it possible to obtain an informative image of the gland, especially its peripheral zones. The advantage of this method is the ability to conduct research in case of difficulties in achieving adequate filling of the bladder (urinary incontinence, neurogenic bladder, etc.). It is important to understand that the ultrasound method of research does not allow detecting all cases of prostate cancer. It is believed that approximately $25 \%$ of all prostate cancer are isoechogenic and poorly differentiated from normal prostate tissue, and in $25 \%$ of cases, prostate tumors develop in transition zones, where their visualization is difficult [11-14]. The urologist should be aware of the features of echographic information obtained through this diagnostic manipulation, and take them into account when determining the optimal scheme for subsequent examination and treatment $[15,16]$. However, these limitations do not in any way cast doubt on the fact that at the present stage of development of instrumental diagnostics TRUS is an essential component of the diagnostic algorithm for diseases of the prostate gland.

\section{RESULTS}

This paper presents data summarizing the experience of the specialist in ultrasound diagnostics at the Rossosh Interdistrict Urological (RIUC) for the detection of prostate diseases in 2018. RIUC provides medical assistance to the population of the Rossosh district (92924 people), Olkhovatka district (22711 people), Kantemirovka district (33999 people), Petropavlovsk district (17152 people). The Center operates on the basis of the Rossosh district hospital. There are 3 specialized urologist specialists at hospital, using ultrasound information from ultrasonic scanners Logic 3, Vivid 3, Ecube 15 equipped with intracavitary sensors.

In total, during 2018, 835 patients were examined, including 543 rural residents and 292 urban residents.

If we consider the different age groups of patients, it should be noted that men aged 50-59 years predominate 300 people $(36 \%)$, followed by the age group from 60 to 69 years - 233 people $(28 \%)$, then men from 39 up to 49 years old - 192 people $(23 \%)$ and the last group of men aged 70 years and over -70 people $(13 \%)$.

For the first time, TRUS of the prostate was performed in 653 people $(78 \%$ ), and again - in 182 people $(22 \%)$. The result of the implementation of this diagnostic procedure was the identification of a wide range of pathological changes in the prostate gland (tab. 1).

TABLE I. PATHOLOGICAL CHANGES IN THE PROSTATE GLAND.

\begin{tabular}{|c|c|c|c|c|c|c|c|c|c|c|}
\hline \multirow{5}{*}{ 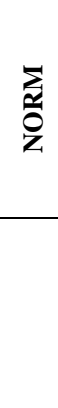 } & \multicolumn{10}{|c|}{ PATHOLOGY } \\
\hline & \multicolumn{10}{|c|}{770} \\
\hline & \multicolumn{3}{|c|}{$B P H$} & \multicolumn{3}{|c|}{$\begin{array}{c}\text { Chronic } \\
\text { Prostatitus }\end{array}$} & \multicolumn{2}{|c|}{$\begin{array}{c}\text { Focal } \\
\text { Formations } \\
(\text { NEO })\end{array}$} & \multicolumn{2}{|c|}{$\begin{array}{c}\text { Condition } \\
\text { after } \\
\text { surgical } \\
\text { treatment }\end{array}$} \\
\hline & \multicolumn{3}{|c|}{537} & \multicolumn{3}{|c|}{182} & \multicolumn{2}{|c|}{23} & \multicolumn{2}{|c|}{28} \\
\hline & D્0 & 总 & $\stackrel{8}{\stackrel{0}{0}}$ & 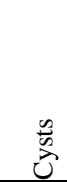 & 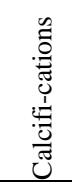 & $\begin{array}{l}\frac{n}{5} \\
0 \\
0 \\
0\end{array}$ & 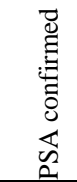 & 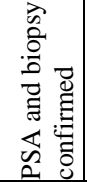 & 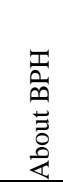 & 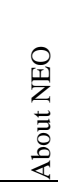 \\
\hline 65 & 288 & 183 & 66 & 36 & 62 & 84 & 15 & 8 & 22 & 6 \\
\hline
\end{tabular}

In addition to identifying cases of malignant lesions of the prostate gland, which seems to be a task of paramount importance, TRUS provides information that clarifies the parameters of other pathological changes in the organ, primarily BPH. In this case, the degree of enlargement of the prostate gland and the type of its growth are of primary importance. Among the examined, BPH was detected in 537 cases. Of these, BPH I degree is in 288 cases, II degree is in 183 cases, III degree is in 66 cases. At the same time, in patients with BPH I degree in 88 cases (30\%), its average lobar type was determined, in $108(37.5 \%)$ - bilateral type and in $92(32.5 \%)$ - mixed type. In patients with grade II BPH, in 26 cases (14\%), its average lobar type was determined, in $113(62 \%)$ - bilateral type and in $45(24 \%)$ mixed type. In patients with grade III BPH, in 8 cases $(12 \%)$, its average lobar type was determined, in $43(65 \%)$ - bilateral type and in $15(23 \%)$ - mixed type. Thus, in patients whose examination revealed $\mathrm{BPH}$, the bilateral type prevailed, 
followed by mixed and mid-lobe growth types. Clinically significant was the information obtained through TRUS of the prostate during the examination of patients with chronic prostatitis. Corresponding changes were identified in 182 men. In this case, the prevailing ultrasound equivalent of the pathological process in 36 cases was a cystic lesion of the gland, in 62 cases - the presence of calcifications, in 84 cases - fibrotic changes.

TABLE II. OTHER PATHOLOGICAL CHANGES.

\begin{tabular}{|c|c|c|c|c|c|c|c|c|}
\hline & & & & BPH & & & & \\
\hline & & & & Total 537 & & & & \\
\hline & I degree & & & II degree & & & III degree & \\
\hline & 288 & & & 183 & & & 66 & \\
\hline \begin{tabular}{|l} 
Av. \\
lobar \\
BPH \\
\end{tabular} & $\begin{array}{l}\text { Bilateral } \\
\mathrm{BPH}\end{array}$ & $\begin{array}{l}\text { Mixed } \\
\text { BPH }\end{array}$ & $\begin{array}{l}\text { Av. } \\
\text { lobar } \\
\text { BPH }\end{array}$ & $\begin{array}{l}\text { Bilateral } \\
\text { BPH }\end{array}$ & $\begin{array}{l}\text { Mixed } \\
\text { BPH }\end{array}$ & $\begin{array}{l}\text { Av. } \\
\text { lobar } \\
\text { BPH }\end{array}$ & $\begin{array}{l}\text { Bilateral } \\
\text { BPH }\end{array}$ & $\begin{array}{l}\text { Mixed } \\
\text { BPH }\end{array}$ \\
\hline $\begin{array}{l}88 \\
(30 \%)\end{array}$ & $\begin{array}{l}108 \\
(37,5 \%)\end{array}$ & $\begin{array}{l}92 \\
(32,5 \%)\end{array}$ & $\begin{array}{l}26 \\
(14 \%)\end{array}$ & $\begin{array}{l}113 \\
(62 \%)\end{array}$ & $\begin{array}{l}45 \\
(24 \%)\end{array}$ & $\begin{array}{l}8 \\
(12 \%)\end{array}$ & $\begin{array}{l}43 \\
(65 \%)\end{array}$ & $\left.\begin{array}{ll}15 & \\
(23 & \% \\
& \end{array}\right)$ \\
\hline
\end{tabular}

\section{CONCLUSION}

It should be noted that prostate cancer was detected in 23 men with TRUS, which was subsequently clinically confirmed as a result of diagnostic measures carried out as part of the regional system of medical care in urology introduced in the Voronezh region. This system made it possible to implement the correct treatment measures. It should be noted that 6 patients underwent control TRUS of the prostate after adequate surgical intervention for each specific case. This indicates the high importance of this diagnostic method to ensure the effectiveness of urological care.

In the process of practical work, the ways of a possible increase in the information content of the TRUS of the prostate gland were noted - first of all, in relation to solving problems of the most complete detection of its malignant formations. It seems advisable to equip the ISC with ultrasound scanners with options for energy and color mapping, which will allow assessing the nature of the blood supply to focal changes in the prostate that are suspicious of malignant tumors. In addition, the information content of the studies will increase the use of diagnostic devices with the possibility of conducting prostate elastography. This makes it possible to identify areas with increased stiffness associated with areas of malignant damage [17-21]. It seems promising to equip diagnostic devices with special biplane transrectal sensors for urological studies, which makes it possible to evaluate the ultrasound picture of the gland in various echographic sections. All of the above will make it possible to bring the diagnostic work at the ISC to a new qualitative level and increase the efficiency of urological care in the regions of the Russian Federation.

\section{References}

[1] A.D. Kaprin, V.V. Starinsky, G.V. Petrova, State of cancer care in Russia in 2018. Moscow: Moscow Cancer Res. Instit. (MNIIO) named after P.A. Herzen, 2019

[2] O.I. Apolikhin, Organization of a three-level system for organizing medical care in urology. Moscow: Uromedia, 2017.

[3] M. Bluth, Mayo Clinic on prostate health. Moscow: AST, 2017.

[4] O.I. Apolikhin, "Distance learning technologies in urology: prospects and development trends, Experience of the Federal state budgetary institution "Research Institute of Urology" of the Ministry of Health of Russia”, Experimental and clinical urology, no. 4, pp. 4-8, 2013.

[5] Y.G. Alyaev, Diseases of the prostate gland. Moscow: GEOTAR-Media, 2012.

[6] Y.G. Alyaev, P.V. Glybochko, D.Y. Pushkar, Urology, Russian clinical recommendations. Moscow: Medforum, 2017.

[7] V. Anichkin, E. Povelitsa, V. Martynyuk, Diagnosis of benign hyperplasia and prostate cancer. Lambert: Acad. Publ., 2014.

[8] E. Efimov, Aspects of early diagnosis of prostate cancer. Lambert: Acad. Publ., 2012.

[9] V.A. Isranov, Ultrasound anatomy of the prostate gland. Moscow: GEOTAR-Media, 2016

[10] D. Kirk, Diseases of the prostate. Moscow: AST. 2013.

[11] G.I. Nazarenko, A.N. Khitrova, Ultrasound diagnostics of the prostate gland in modern urological practice. Moscow: Vidar, 2012.

[12] D.Y. Pushkar, Diagnosis and treatment of localized prostate cancer. Moscow: Medpress-inform, 2018.

[13] V.E., Rodoman, Diseases of the prostate. Guide for doctors. Moscow: Medical News Agency, 2011.

[14] O.L. Tiktinsky, S.N. Kalinina, Diseases of the prostate. Moscow: Peter, 2018.

[15] T.I. Listovsky, Treatment of diseases of the prostate. Moscow: Book house, 2013.

[16] A.F. Tsyb, Radiation therapy for prostate cancer, Guide for doctors. Moscow: Medical book, 2010

[17] V.V. Mitkov, A.K. Vasilyeva, M.D. Mitkova, "Possibilities of ultrasound elastography in the diagnosis of prostate cancer", Ultrasound and functional diagnostics, vol. 3, pp. 18-24, 2012.

[18] V.V. Mitkov, A.K. Vasilyeva, M.D. Mitkova, "Ultrasonic elastography of the shear wave in patients with, Materials and methods Azarova N.A., Nebesnaya A.Y., Sviridov A.S., Glagoleva L.E. Analysis of human capital in the region as a source of import substitution", Proc. of the Voronezh State Univer. of Engineer. Technol., vol. 80, no. 3, pp. 451-457, 2018. Retrieved from: https://doi.org/10.20914/2310-12022018-3-451-457

[19] I.A. Kiseleva, N.E. Simonovich, E.D. Solomatina, "Social well-being of people and the strategy of innovative development of the enterprise", Proc. of the Voronezh State Univer. of Engineer. Technol., vol. 81, no. 1, pp. 402-411, 2019. Retrieved from: https://doi.org/10.20914/2310-12022019-1-402-411 